\title{
Coronal Restoration as a Predictor of Periapical Disease in Non- Endodontically Treated Teeth
}

\section{Koronarna restauracija kao predskazatelj periapikalne bolesti u endodontski neliječenim zubima}

\footnotetext{
${ }^{1}$ Department of Endodontics and Restorative Dentistry, Rijeka Clinical Hospital Centre, Faculty of Dental Medicine, University of Rijeka, Rijeka, Croatia

Zavod za endodonciju i restaurativnu stomatologiju Kliničkoga bolničkog centra Rijeka, Fakultet dentalne medicine Sveučilišta u Rijeci, Hrvatska

2 Department of Oral Medicine and Periodontology, Rijeka Clinical Hospital Centre, Faculty of Dental Medicine, University of Rijeka, Rijeka, Croatia

Zavod za oralnu medicinu i parodontologiju Kliničkoga bolničkog centra Rijeka, Fakultet dentalne medicine Sveučilišta u Rijeci, Hrvatska
}

\section{Abstract}

Objectives: To compare the frequency of apical periodontitis (AP) in non-endodontically treated teeth restored with full coverage crowns, amalgam and resin composite fillings, and to disclose the association of type and quality of coronal restoration with periapical disease. Material and methods: The cross-sectional study involved 597 subjects who attended the Dental Clinic of the Clinical Hospital Centre, Rijeka, Croatia for the first time. Data were collected by means of a clinical and radiological survey. The following data were recorded for all permanently restored non-endodontically treated teeth: the type, the quality of coronal restoration according to clinical and radiographic criteria for marginal integrity as well as the recurrent caries presence, periapical status and marginal bone loss. Chi-square tests were used to analyze the difference in periapical status regarding the type and the quality of restoration. The multivariate logistic regression analysis was used to assess the effect of explanatory tooth-specific variables on periapical status. Results: There was no significant difference in the proportion of AP with regards to the type and material of adequate quality coronal restorations $\left(\chi^{2}=5.000, P=0.082\right)$. The regression analysis revealed significant positive associations with outcome variable $(A P)$ for crowns $(O R=3.39 ; P<0.001)$, recurrent caries $(O R=4.67 ; P<0.001)$ and premolar teeth $(\mathrm{OR}=1.73 ; \mathrm{P}=0.002)$. Conclusion: If the quality of restorations is adequate, there is no difference in the periapical status of non-endodontically treated teeth regarding the type and material of coronal restoration.
Received: June 20, 2020

Accepted: January 4, 2021

Address for correspondence Romana Peršić Bukmir, DMD, Ph.D. University of Rijeka, Rijeka, Croatia Rijeka Clinical Hospital Centre, Faculty of Dental Medicine Department of Endodontics and Restorative Dentistry, ORCID: 0000-0002-5325-6726 Kresimirova 40, 51000 Rijeka, Croatia Phone: +385 51345635

Fax: +385 51345630 rpersic@gmail.com

MeSH terms: Tooth Crown; Permanent Dental Restoration; Dental Amalgam; Composite Resins; Periapical Periodontitis;

Author keywords: Composite Resins; Crowns; Dental Amalgam; Dental Caries; Periapical Periodontitis

\section{Introduction}

Apical periodontitis (AP) is a common inflammatory disease affecting periapical tissues due to microbial infection of root canals. The incidence of AP varies greatly among countries considering the differences in sampling methods and diagnostic criteria (1). A study on the prevalence of AP in Croatian adults reported the presence of periapical disease in $8.5 \%$ of the examined teeth (2). Several risk indicators specific for the occurrence of AP have been identified. A significantly increased risk for the presence of AP was reported for teeth restored with coronal fillings or crowns, teeth with primary caries, endodontically treated teeth, and molars (3). A longitudinal epidemiologic study reported an association of
Uvod

Apikalni parodontitis (AP) česta je upalna bolest koja zahvaća periapikalna tkiva, a nastaje zbog mikrobne infekcije korijenskih kanala. Njegova se incidencija uvelike razlikuje između zemalja zbog različitih metoda uzorkovanja i dijagnostičkih kriterija (1). U istraživanju u kojemu su autori istraživali pojavnost AP-a na uzorku odraslih Hrvata, utvrđena je periapikalna bolest na $8,5 \%$ pregledanih zuba (2). Prepoznato je nekoliko rizičnih čimbenika specifičnih za pojavu APa. Značajno povećani rizik za tu bolest imali su zubi opskrbljeni koronarnim ispunima ili krunicama, zubi s primarnim karijesom, endodontski liječeni zubi i kutnjaci (3). U longitudinalnoj epidemiološkoj studiji uočena je povezanost AP-a 
periapically diseased non-endodontically treated teeth with the presence of coronal restoration of poor quality or carious lesion (4). However, limited data on the association of AP and type of coronal restoration in non-endodontically treated teeth are available.

Despite recommendations for a global phase-down, amalgam is still widely applied material for restoration of posterior teeth in certain countries due to its low cost and effectiveness (Minamata Convention on Mercury). In Croatia, amalgam is mostly utilized in dental settings because it provides dental care through the health insurance system. Alternatively, resin composite restorations require highly demanding adhesive procedure that can be challenging in oral environment. Furthermore, polymerization shrinkage, stress, debonding and marginal leakage as the main causes of adhesive restorations failure can lead to pulpal breakdown, and subsequently to AP (5). Low-quality evidence suggested a higher failure rate in resin composite restorations and an increased risk of recurrent caries in contrast to amalgam restorations (6). An in vitro study found that microleakage was significantly higher in composite than amalgam restorations (7). A cross-sectional study conducted in Sweden hypothesized that teeth restored with composite resin restorations exhibit AP more frequently than teeth restored with amalgam restorations, yet no significant differences in the frequency of periapical pathology regarding these materials were found (8).

Several studies reported higher prevalence rates of AP in teeth restored with crowns $(8,9)$. However, long-term follow-up studies reported low incidence of radiographically detectable periapical lesions in crowned teeth $(10,11)$. A study investigating factors related to pulpal breakdown in vital teeth restored with metal-ceramic crowns suggested a significantly higher survival of the pulp vitality in single crowned teeth than in teeth that served as abutments of a fixed bridge (12).

The hypothesis for the present study was that the periapical status of non-endodontically treated teeth does not vary with regards to the type of permanent coronal restorations. The purpose was to compare the frequency of AP in non-endodontically treated teeth restored with full coverage crowns, amalgam and resin composite fillings, as well as to disclose the association of type and quality of coronal restoration with the presence of AP.

\section{Material and methods}

This cross-sectional study received ethical approval from the Institutional Ethical Committee (003-05/13-01/03). The sample that formed the basis for the study consisted of 1072 patients older than 18 years, who attended Dental Clinic of the Clinical Hospital Centre, Rijeka, Croatia for the first time and who presented consecutively within two years. The patients were not included if they refused to participate, had seven or less remaining teeth, received endodontic therapy within two years, and were unwilling or unable to attend the radiographic diagnostics. The implementation of these criteria provided the sample of 597 subjects (Figure 1). All participants accepted to take part by signing an informed consent. $\mathrm{u}$ endodontski neliječenim zubima s koronarnom restauracijom loše kvalitete te karijesom (4). No ograničeni su podatci o povezanosti AP-a u endodontski neliječenim zubima s vrstom koronarne restauracije.

Unatoč preporukama da se postupno sve rjeđe upotrebljava, amalgam se u određenim zemljama i dalje često koristi u restauraciji stražnjih zuba zbog niske cijene i zadovoljavajuće učinkovitosti (Minamatska konvencija o živi). U Hrvatskoj se većinom koristi u dentalnim ordinacijama ustrojenima u sustavu javnoga zdravstvenog osiguranja. Suprotno tomu, izrada kompozitnih restauracija podrazumijeva tehnički zahtjevan adhezivni postupak čija je izrada izazov u uvjetima usne šupljine. Glavni uzroci za neuspjeh adhezivne restauracije - polimerizacijsko skupljanje, stres, popuštanje adhezivne veze i rubno propuštanje - mogu prouzročiti upalu pulpe i posljedično rezultirati AP-om (5). Manje pouzdana istraživanja upućuju na višu stopu neuspjeha kompozitne restauracije, uz povećan rizik od nastanka rekurentnog karijesa u usporedbi s amalgamskim restauracijama (6). U studiji in vitro istraživači su ustanovili više mikropropuštanja u kompozitnim restauracijama negoli u amalgamskima (7). U presječnom istraživanju provedenom u Švedskoj autori su pretpostavili da će se AP češće pojaviti na zubima restauriranima kompozitnim restauracijama negoli amalgamskima. Ipak, nisu pronađene značajne razlike u učestalosti periapikalne patologije s obzirom na te materijale (8).

U nekoliko istraživanja upozoreno je na veću učestalost AP-a u zubima restauriranima krunicama $(8,9)$. No u longitudinalnim studijama istraživači su utvrdili nisku incidenciju radiološki vidljivih periapikalnih lezija u zubima restauriranima krunicama $(10,11)$. U istraživanju u kojemu se proučavala pojava upale pulpe u vitalnim zubima opskrbljenima krunicama uočeno je značajno veće očuvanje njezine vitalnosti kada su zubi bili restaurirani pojedinačnim krunicama negoli ako su bili nosači fiksnoga protetičkoga rada (12).

Hipoteza u ovom istraživanju bila je da vrsta trajne koronarne restauracije ne utječe na periapikalni status endodontski neliječenih zuba. Svrha je bila usporediti učestalost AP-a $\mathrm{u}$ endodontski neliječenim zubima restauriranima potpunim krunicama, amalgamskim i kompozitnim ispunima, te otkriti povezanost vrste i kvalitete koronarne restauracije s prisutnošću AP-a.

\section{Materijal i metode}

Ovo presječno istraživanje odobrilo je lokalno etičko povjerenstvo (003-05/13-01/03). Uzorak se sastojao od 1072 pacijenta starija od 18 godina koji su, u razdoblju od dvije godine, prvi put posjetili Kliniku za dentalnu medicinu Kliničkoga bolničkog centra Rijeka. Pacijenti nisu bili uključeni u istraživanje ako su odbili sudjelovati, imali su sedam ili manje preostalih zuba, bili su podvrgnuti endodontskom liječenju u prethodne dvije godine te su odbili radiološku dijagnostiku ili su joj bili u nemogućnosti pristupiti. Primjenom tih kriterija dobiven je uzorak od 597 ispitanika (slika 1.). Svi su potpisali informirani pristanak. Istraživanje je provedeno u skladu s načelima Helsinške deklaracije Svjetskoga medicin- 


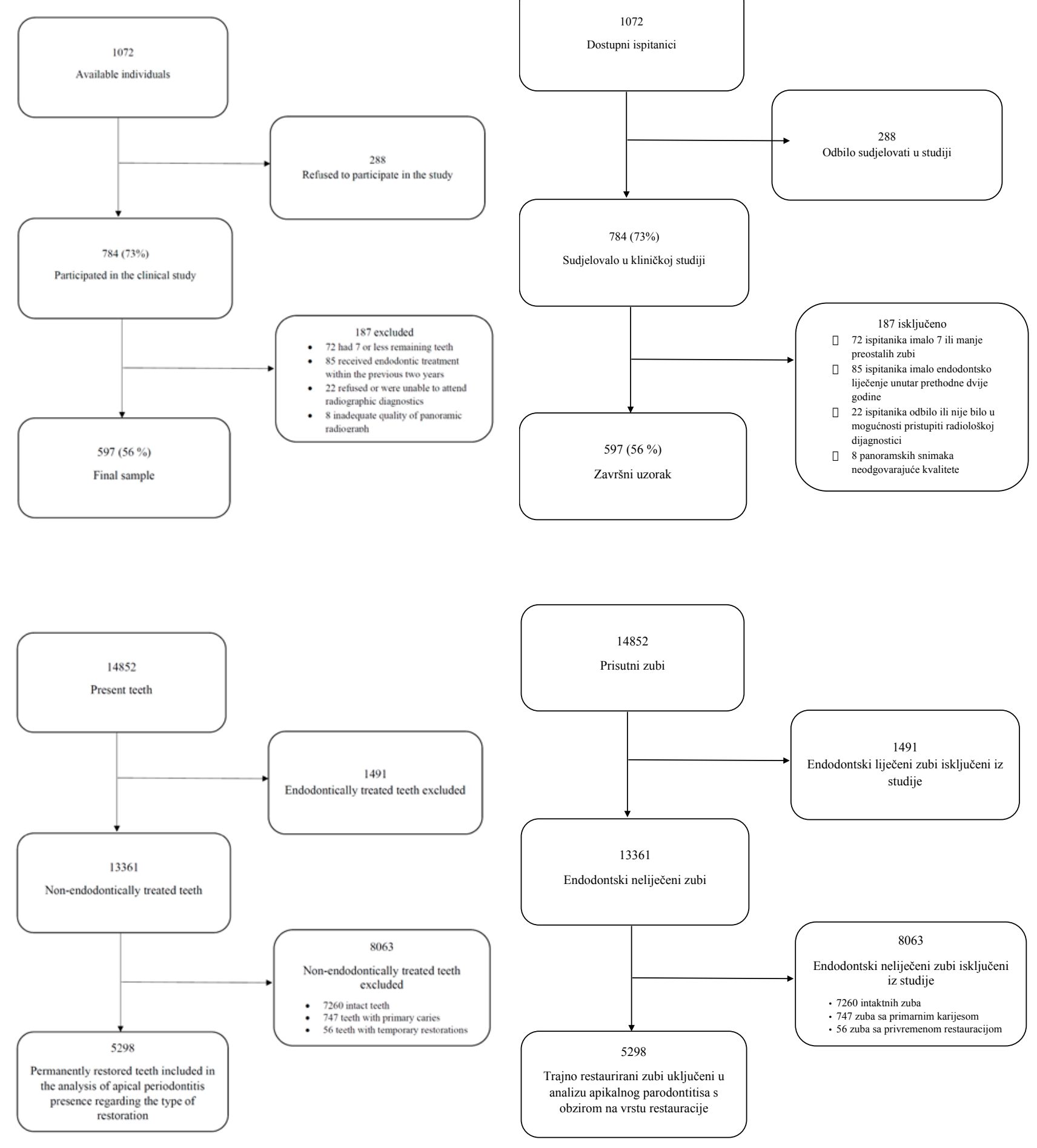

Figure 1 Flowchart demonstrating patient enrolment in the study

Slika 1. Dijagram koji pokazuje uključivanje pacijenata u istraživanje

Figure 2 Flowchart demonstrating teeth enrolment in the analysis of apical periodontitis presence regarding the type of restoration

Slika 2. Dijagram koji pokazuje uključivanje zuba u analizi prisutnosti apikalnog parodontitisa s obzirom na vrstu restauracije 
The study was conducted in accordance with the World Medical Association Declaration of Helsinki principles.

Data were collected by means of a clinical and radiographic survey. The radiographic survey included digital panoramic radiographs and 4 bitewings (revealing the distal surface of canine to mesial surface of the last molar). Panoramic images were obtained by utilizing a panoramic digital radiography device (J. Morita Corporation, Veraviewepocs 6716, Kyoto, Japan) with exposure parameters following the manufacturer's recommendation depending on the patient's size and weight (70 - $90 \mathrm{kV}, 10-15 \mathrm{~mA}$, and $14 \mathrm{~s}$ of exposure). Images were processed using software (Mediadent V4, Image Level, Nieuwkerkenwaas, Belgium). Bitewings were taken using an X-ray unit (Trophy Elitys, Trophy Radiologie, Marne-la-Vallee, France) and an intraoral sensor (One, Owandy Radiology, Roslyn, NY, USA). The exposure parameters used were $60 \mathrm{kV}, 7 \mathrm{~mA}$ and $0.32 \mathrm{~s}$. Panoramic and bitewing images were analyzed on a 19-inch liquid crystal monitor (P1914S; Dell, Austin, TX, USA; resolution:1,280 x 1,024 32-bit color; graphic card: HD Graphic; Intel, Santa Clara, CA, USA).

The following data were recorded for all present teeth, apart from third molars and impacted teeth: coronal status (intact tooth, primary caries, temporary restoration, permanent restoration), the presence of endodontic treatment and periapical status. For diagnosis of dental caries, the WHO diagnostic thresholds were used (World Health Organization 1997; 13). The total number of teeth present in the sample for this survey was 14852 . The analyses of AP presence regarding the quality and type of coronal restoration were performed on 5298 permanently restored non-endodontically treated teeth. All endodontically treated teeth and 8063 nonendodontically treated teeth (intact teeth, teeth with primary caries or temporary restoration) were omitted from further analysis (Figure 2).

\section{Assessment of restorations}

Using the recordings from clinical examination and interpretation of radiographic images (panoramic radiographs and bitewings), following data for all non-endodontically treated teeth with permanent restorations were noted: type (filling or crown), material (amalgam or resin composite) and quality of restoration according to clinical and radiological criteria for marginal integrity and recurrent caries presence. The clinical quality of coronal restorations was evaluated in accordance with modified United States Public Health Service/ Ryge (USPHS/Ryge) criteria for marginal integrity and recurrent caries as reported by Merdad et al. (14). Radiographically, marginal integrity of the restoration was defined as adequate (radiographically sealed) or inadequate (signs of open margins or overhangs) according to previously described criteria (15). Recurrent caries was noted as absent or present (clearly visible reduction in mineral content of a proximal tooth surface contiguous with a restoration; 16).

\section{Assessment of periapical status and marginal bone} loss

Analysis of the marginal bone loss and periapical status was accomplished using digital panoramic radiographs. The loss of the marginal bone was designated as less or more than skog udruženja (engl. World Medical Association Declaration of Helsinki principles).

Podatci su prikupljeni kliničkim i radiološkim pregledom. Radiološki pregled obuhvaćao je analizu digitalne panoramske snimke i četiri snimke s ugrizom u traku (područja od distalne plohe očnjaka do mezijalne plohe zadnjeg kutnjaka). Panoramske snimke izrađene su s pomoću uređaja za digitalnu radiografiju (J. Morita Corporation, Veraviewepocs 6716, Kjoto, Japan). Parametri izloženosti prilagođeni su prema uputama proizvođača s obzirom na veličinu i težinu pacijenta (70 - 90 kV, 10 - 15 mA i 14 s izloženosti). Snimke su obrađene u računalnom programu (Mediadent V4, Image Level, Nieuwkerkenwaas, Belgija). Za izradu snimki s ugrizom u traku korišten je rendgenski uređaj (Trophy Elitys, Trophy Radiologie, Marne-la-Vallee, Francuska) s intraoralnim senzorom (One, Owandy Radiology, Roslyn, NY, SAD). Primijenjeni parametri izlaganja bili su $60 \mathrm{kV}, 7 \mathrm{~mA}$ i 0,32 s. Rendgenske snimke analizirane su na 19-inčnom monitoru na temelju tehnologije tekućih kristala (P1914S; Dell, Austin, TX, SAD; rezolucija:1,280 x 1,024 32-bit boja; grafička kartica: HD Graphic; Intel, Santa Clara, CA, SAD).

Osim impaktiranih zuba i trećih kutnjaka pregledani su svi zubi te su zabilježeni sljedeći podatci: koronarni status (intaktni zub, primarni karijes, privremena restauracija, trajna restauracija), endodontsko liječenje i periapikalni status. $\mathrm{U}$ dijagnozi dentalnog karijesa korišsteni su dijagnostički kriteriji Svjetske zdravstvene organizacije (SZO 1997.; 13). Ukupan broj pregledanih zuba u ovom istraživanju bio je 14852 . Kod 5298 trajno restauriranih endodontski neliječenih zuba analizirana je prisutnost AP-a s obzirom na kvalitetu i vrstu koronarne restauracije. Svi endodontski liječeni zubi te 8063 neliječena zuba (koji su bili intaktni, imali primarni karijes ili privremenu restauraciju) isključeni su iz daljnje analize (slika 2.).

\section{Procjena restauracija}

Kliničkim i radiološkim pregledom prikupljeni su sljedeći podatci za sve endodontski neliječene trajno restaurirane zube: vrsta (ispun ili krunica), materijal (amalgam ili kompozit) i kvaliteta restauracije $s$ obzirom na kliničke i radiološke kriterije marginalnog integriteta i pojave rekurentnog karijesa. Klinički je kvaliteta koronarne restauracije procijenjena prema modificiranim Rygeovim USPHS kriterijima (engl. United States Public Health Service) za rubnu cjelovitost restauracije i rekurentni karijes (14). Radiološki je rubna cjelovitost restauracije definirana prema već opisanim kriterijima kao odgovarajuća (radiološki vidljivo brtvljenje rubova) ili neodgovarajuća (radiološki vidljivi otvoreni rubovi restauracije ili prevjes) (15). Rekurentni karijes zabilježen je kao odsutan ili prisutan (jasno vidljivo smanjenje mineralnog sadržaja aproksimalne površine zuba u dodiru s restauracijom; 16).

\section{Procjena periapikalnog statusa i gubitka marginalne kosti}

Gubitak marginalne kosti i periapikalni status određeni su analizom digitalnih panoramskih snimki. Određen je kao gubitak više ili manje od trećine dužine korijena (9). Peria- 
one third of the root length (9). The periapical status was analyzed using the periapical index system (PAI; 17). Each tooth was scored using visual references for the full-scale PAI. To define the periapical status in multirooted teeth, the highest PAI value of all roots was used. The full-scale scores were dichotomized, and periapical status was registered as healthy (PAI scores 1 and 2) or AP (PAI scores 3, 4 and 5).

\section{Calibration procedures}

The PAI calibration was accomplished by evaluation of periapical status in 100 reference teeth (17). After each tooth was given one of the five PAI scores, a comparison to gold standard scores was made, and a Cohen's Kappa was calculated (0.70). Calibrations for diagnosis of dental caries, coronal restoration quality and marginal bone loss were performed according to WHO recommendations (13). Diagnostic intraexaminer agreement was analyzed by double scoring of the 30 randomly selected individuals' clinical and radiographic surveys. Intra-examiner agreement was determined by calculating Cohen's Kappa for clinical and radiographic diagnosis of recurrent caries ( 0.85 and 0.92 , respectively), clinical and radiographic assessment of marginal integrity $(0.81$ and 0.85 , respectively), PAI (0.75) and marginal bone loss (0.89).

\section{Statistical analysis}

For statistical analysis, a software (Statistica 13.0, Statsoft , Tulsa, OK, USA) was used, at level of statistical significance $\mathrm{P}<0.05$. To test data for distribution normality Lilliefors test was used. As the distribution of data was not normal, median and interquartile range were used to report central tendency and dispersion. Mann-Whitney $U$ test was used to test the differences between the groups regarding the continuous variables. Chi-square tests were used to analyze the variations in periapical status regarding the type and quality of restoration as well as tooth type. Multivariate logistic regression pikalni status analiziran je uporabom periapikalnog indeksa (engl. periapical indeks - PAI; 17). PAI svakoga zuba određen je primjenom vizualne referencije za sveobuhvatnu ljestvicu PAI-ja. U određivanju periapikalnog statusa višekorijenskih zuba uzimao se najviši iznos PAI-ja pojedinog korijena. Vrijednosti sveobuhvatne ljestvice su dihotomizirane te je periapikalni status zuba zabilježen kao zdrav (PAI vrijednosti 1 i 2) ili kao AP (PAI vrijednosti 3, 4 i 5).

\section{Postupak kalibracije}

PAI kalibracija provedena je procjenom periapikalnog statusa 100 referentnih zuba (17). Nakon što je svakomu dana jedna od vrijednosti PAI-ja, napravljena je usporedba sa zlatnim standardnom te je izračunata vrijednost Cohenova kappa koeficijenta $(0,70)$. Kalibracije za dijagnostiku dentalnog karijesa te određivanje kvalitete koronarne restauracije i gubitka marginalne kosti provedene su prema preporukama SZO-a (13). Utvrđivanje intrapodudarnosti istraživača provedeno je ponovljenom analizom kliničke i radiološke dokumentacije 30 nasumično odabranih ispitanika. Intrapodudarnost istraživača određena je izračunom Cohenova kappa koeficijenta za kliničku i radiološku dijagnozu rekurentnog karijesa $(0,85$, odnosno 0,92$)$, zatim za kliničku i radiološku procjenu rubne cjelovitosti restauracije $(0,81$, odnosno 0,85$)$, PAI $(0,75)$ te gubitak marginalne kosti $(0,89)$.

\section{Statistička analiza}

U statističkoj analizi korišten je računalni program (Statistica 13.0, Statsoft , Tulsa, OK, SAD) na razini značajnosti $\mathrm{p}<0,05$. U testiranju raspodjele podataka korišten je Lillieforsov test. $S$ obzirom na to da je raspodjela podataka odstupala od normalne, za prikaz centralne tendencije i raspršenja podataka korišsteni su medijan i interkvartilni raspon. MannWhitneyjev U-test primijenjen je u testiranju razlika između grupa s obzirom na kontinuirane varijable. Hi-kvadrat testovi korišteni su u analizi varijacija periapikalnog statusa u odnosu prema vrsti i kvaliteti restauracije te skupini kojoj zub

Table 1 Independent variables used in multivariate logistic regression analysis

Tablica 1. Nezavisne varijable korištene u multivarijantnoj logističkoj regresijskoj analizi

Type of restoration $\bullet$ Vrsta restauracije

Amalgam filling $\bullet$ Amalgamski ispun

Composite resin filling $\bullet$ Kompozitni smolasti ispun

Crown $\bullet$ Krunica

Marginal integrity of restoration (clinically and radiographically) • Rubna cjelovitost restauracije (klinički i radiološki)

\begin{tabular}{l|l} 
Adequate $\bullet$ Odgovarajuća & No defective restoration margin $\bullet$ Nema defektnih rubova restauracije \\
\hline Inadequate $\bullet$ Neodgovarajuća & Defective restoration margin $\bullet$ Defektni rubovi restauracije
\end{tabular}

Recurrent caries (clinically and radiographically) • Rekurentni karijes (klinički i radiološki)

\begin{tabular}{l|l}
$\mathrm{No} \bullet \mathrm{Ne}$ & $\begin{array}{l}\text { No detectable caries contiguous with a restoration } \bullet \text { Nema vidljivog karijesa u dodiru s } \\
\text { restauracijom }\end{array}$ \\
\hline Yes $\bullet \mathrm{Da}$ & Detectable caries contiguous with restoration $\bullet$ Vidljiv karijes u dodiru s restauracijom
\end{tabular}

\section{Tooth type $\bullet$ Grupa zuba}

Incisors and canines $\bullet$ Sjekutići i očnjaci

Premolars $\bullet$ Pretkutnjaci

Molars $\bullet$ Kutnjaci

\section{Marginal bone loss (radiographically) • Gubitak marginalne kosti (radiološki)}

No marginal bone loss $\bullet$ Nema gubitka marginalne kosti $\leq 1 / 3$ root length $\bullet \leq 1 / 3$ dužine korijena

\begin{tabular}{l|l} 
Marginal bone loss $\bullet$ Gubitak marginalne kosti & $>1 / 3$ root length $\bullet>1 / 3$ dužine korijena
\end{tabular}

*First category was used as reference category • Prva kategorija korištena je kao referentna kategorija 
analysis was used to assess the effect of explanatory tooth-specific variables (type of restoration, marginal integrity, recurrent caries, tooth type and marginal bone loss) on periapical status. All explanatory variables are provided in table 1 . The outcome variable was defined as the presence versus absence of $A P$ in the tooth.

\section{Results}

The final sample involved 190 male (31.8\%) and $407 \mathrm{fe}-$ male participants (68.2\%). The median age of participant was 34 years (interquartile range 24 - 46). No difference in age was detected regarding participants'sex (Mann-Whiney $\mathrm{U}$ test; $\mathrm{P}=0.534)$. The median number of remaining teeth ranged from 27 in the youngest age group to 22 in the oldest age group. On the average, an examined individual had 1 non-endodontically treated tooth with AP (interquartile range $0-1$ ). The presence of AP in 1or more non-endodontically treated teeth was recorded in $54.3 \%$ of the examined participants (Table 2).

AP was diagnosed in $286(5.4 \%)$ permanently restored non-endodontically treated teeth. The frequency of AP in re- pripada. Multivarijantnom logističkom regresijom raščlanjen je učinak varijabli specifičnih za zub (vrsta restauracije, rubna cjelovitost, rekurentni karijes, skupina zuba i gubitak marginalne kosti) na periapikalni status. Sve opisne varijable navedene su u tablici 1. Ishodišna varijabla definirana je kao prisutnost ili odsutnost AP-a na zubu.

\section{Rezultati}

Ukupan uzorak činilo je 190 muškaraca (31,8 \%) i 407 žena $(68,2 \%)$. Medijan dobi sudionika iznosio je 34 (interkvartilni raspon $24-46)$. Nije uočena razlika u godinama sudionika s obzirom na spol (Mann-Whitneyjev U-test; P = 0,534). Medijan broja preostalih zuba bio je u rasponu od 27 u najmlađoj dobnoj skupini, do 22 zuba u najstarijoj. U prosjeku su ispitanici imali jedan endodontski neliječeni zub $s$ AP-om (interkvartilni raspon 0 - 1). Kod 54,3\% ispitanika uočen je AP na jednom ili više endodontski neliječenih zuba (tablica 2.).

AP je dijagnosticiran na $286(5,4 \%)$ trajno restauriranih endodontski neliječenih zuba. U tablici 3. prikazana je učestalost AP-a s obzirom na vrstu i kvalitetu koronarne resta-

Table 2 Distribution of all examined individuals regarding age, dental and periapical status

Tablica 2. Raspodjela svih pregledanih ispitanika s obzirom na dob te dentalni i periapikalni status

\begin{tabular}{|c|c|c|c|c|c|}
\hline $\begin{array}{c}\text { Age } \\
\text { Dob }\end{array}$ & $\begin{array}{c}\text { Examined } \\
\text { individuals } \\
\text { Pregledani } \\
\text { ispitanici } \\
\text { n }\end{array}$ & $\begin{array}{l}\text { Remaining teeth (median, } \\
\text { interquartile range) } \\
\text { Preostali zubi (medijan, } \\
\text { interkvartilni raspon) }\end{array}$ & $\begin{array}{l}\text { Intact teeth (median, } \\
\text { interquartile range) } \\
\text { Intaktni zubi (medijan, } \\
\text { interkvartilni raspon) }\end{array}$ & $\begin{array}{l}\text { Non-endodontically treated } \\
\text { teeth with AP (median, } \\
\text { interquartile range) } \\
\text { Endodontski neliječeni } \\
\text { zubi s AP-om (medijan, } \\
\text { interkvartilni raspon) }\end{array}$ & $\begin{array}{c}\text { Individuals with } 1 \text { or more } \\
\text { non-endodontically treated } \\
\text { teeth with AP } \bullet \text { Ispitanici } \\
s \text { jednim endodontski } \\
\text { neliječenim zubom } s \text { AP-om } \\
\text { ili više njih } \\
\text { n (\%) }\end{array}$ \\
\hline$<29$ & 244 & $27(26-28)$ & $16(12-18)$ & $1(0-1)$ & $110(45.1)$ \\
\hline $30-39$ & 129 & $27(25-28)$ & $14(10-16)$ & $0(0-1)$ & $70(54.3)$ \\
\hline $40-49$ & 105 & $25(24-26)$ & $10(9-14)$ & $0(0-1)$ & $70(66.7)$ \\
\hline $50-59$ & 69 & $24(21-24)$ & $8(4-10)$ & $1(0-2)$ & $39(56.5)$ \\
\hline$>60$ & 50 & $22(13-23)$ & $7(2-10)$ & $1(0-2)$ & $35(70.0)$ \\
\hline $\begin{array}{l}\text { Total• } \\
\text { Ukupno }\end{array}$ & 597 & $26(24-28)$ & $12(9-16)$ & $1(0-1)$ & $324(54.3)$ \\
\hline
\end{tabular}

AP-apical periodontitis $\bullet$ apikalni parodontitis

The percentages are calculated out of examined patients in each age group. • Postotci su izračunati na temelju broja pregledanih pacijenata u svakoj dobnoj skupini.

Table 3 Type and quality of coronal restoration in relation to AP

Tablica 3. Vrsta i kvaliteta koronarne restauracije s obzirom na AP

\begin{tabular}{|c|c|c|c|c|c|c|c|c|c|}
\hline \multirow{3}{*}{$\begin{array}{c}\text { Type/material of } \\
\text { restoration • } \\
\text { Vrsta/materijal } \\
\text { restauracije }\end{array}$} & \multirow{2}{*}{\multicolumn{3}{|c|}{$\begin{array}{l}\mathrm{AP} \text { in relation to restoration } \\
\mathrm{AP} \text { u odnosu prema restauraciji }\end{array}$}} & \multicolumn{6}{|c|}{$\mathrm{AP}$ in relation to restoration quality $\bullet \mathrm{AP} \mathbf{u}$ odnosu prema kvaliteti restauracije } \\
\hline & & & & \multicolumn{3}{|c|}{ Adequate quality • Odgovarajuća kvaliteta } & \multicolumn{3}{|c|}{$\begin{array}{c}\text { Inadequate quality • } \\
\text { Neodgovarajuća kvaliteta }\end{array}$} \\
\hline & $\begin{array}{l}\text { Total } \\
\text { Ukupno }\end{array}$ & $\mathrm{AP}, \mathrm{n}(\%)$ & $\begin{array}{l}\text { Statistics • } \\
\text { Statistika }\end{array}$ & $\begin{array}{l}\text { Total • } \\
\text { Ukupno }\end{array}$ & AP, $\mathbf{n}(\%)$ & $\begin{array}{l}\text { Statistics } \\
\text { Statistika }\end{array}$ & $\begin{array}{l}\text { Total } \\
\text { Ukupno }\end{array}$ & $\mathrm{AP}, \mathrm{n}(\%)$ & $\begin{array}{l}\text { Statistics } \bullet \\
\text { Statistika }\end{array}$ \\
\hline Amalgam & 1363 & $70(5.1)$ & \multirow{3}{*}{$\begin{array}{l}\chi^{2}=35.344 \\
P<0.001^{*}\end{array}$} & 768 & $14(1.8)$ & \multirow{3}{*}{$\begin{array}{l}\chi^{2}=5.000 \\
P=0.082 \dagger\end{array}$} & 595 & $56(9.4)$ & \multirow{3}{*}{$\begin{array}{l}\chi^{2}=44.953 \\
P<0.001^{*}\end{array}$} \\
\hline $\begin{array}{l}\text { Composite • } \\
\text { Kompozit }\end{array}$ & 3551 & $170(4.8)$ & & 1912 & $40(2.1)$ & & 1639 & $130(7.9)$ & \\
\hline Crown $\bullet$ Krunica & 384 & $46(12.0) \ddagger$ & & 239 & $10(4.2)$ & & 145 & $36(24.8) \ddagger$ & \\
\hline Total • Ukupno & 5298 & $286(5.4)$ & & 2919 & $64(2.2)$ & & 2379 & $222(9.3)$ & \\
\hline
\end{tabular}

*Significant differences in frequency of teeth with AP according to type of coronal restoration $\bullet$ Značajne razlike u učestalosti zuba s AP-om s obzirom na vrstu koronarne restauracije

$\dagger$ †o significant difference in frequency of teeth with AP according to type of coronal restoration • Nema značajne razlike u učestalosti zuba s AP-om s obzirom na vrstu koronarne restauracije

$\ddagger$ Significant differences vs both other types of coronal restoration $\bullet$ Značajne razlike vs. obje druge vrste koronarne restauracije 
lation to the type and quality of coronal restorations is demonstrated in Table 3. A significant difference in the prevalence of teeth with AP according to the type of coronal restoration was present $\left(\chi^{2}=35.344, \mathrm{P}<0.001\right)$. The frequency of AP in teeth restored with crowns was significantly higher than in the teeth restored with amalgam $(12.0 \%$ vs $5.1 \% ; \mathrm{P}<0.001)$ or those restored with composite fillings $(12.0 \%$ vs $4.8 \% ; \mathrm{P}<0.001)$. If the overall quality of restoration was adequate, there were no significant differences in the proportion of AP with regards to type of coronal restoration $\left(\chi^{2}=5.000, P=0.082\right.$; Table 3$)$.

Table 4 demonstrates the distribution of teeth with AP in relation to the tooth group, quality and type of coronal restoration. Significant differences in the proportion of teeth diagnosed with AP regardless of the quality of coronal restoration were detected in the group of premolars $\left(\chi^{2}=12.872\right.$; $\mathrm{P}=0.002)$ and molars $\left(\chi^{2}=34.468 ; \mathrm{P}<0.001\right)$. In the premolar group, AP was more commonly detected in crowned teeth than in teeth restored with amalgam ( 13.4 vs $4.3 ; \mathrm{P}=0.002)$ or composite fillings ( 13.4 vs $5.9 ; \mathrm{P}=0.003)$. Molars restored with crowns were also more often diagnosed with AP than molars restored with amalgam $(19.0$ vs $5.4 ; \mathrm{P}<0.001)$ or composite fillings ( 19.0 vs $4.1 ; \mathrm{P}<0.001)$. However, only the group of premolars demonstrated significant differences regarding the type of coronal restoration $(\chi 2=19.786 ; \mathrm{P}<0.001)$ in teeth with adequate quality of coronal restoration. AP was more common in premolars restored with crowns, than those restored with amalgam or composite fillings (11.9\% vs $1.9 \%$ and 3\%, respectively; both $\mathrm{P}<0.001$; Table 4). uracije. Uočena je značajna razlika u učestalosti zuba s APom s obzirom na vrstu koronarne restauracije $\left(\chi^{2}=35,344\right.$, $\mathrm{P}<0,001)$. AP je bio češći u zubima koji su restaurirani krunicama u usporedbi $s$ amalgamskim $(12,0 \%$ vs. $5,1 \%$; $\mathrm{P}<$ $0,001)$ ili kompozitnim ispunima $(12,0 \%$ vs. $4,8 \%$; $\mathrm{P}<$ $0,001)$. Ako je kvaliteta restauracije bila primjerena, nije pronađena značajna razlika u učestalosti $\mathrm{AP}$-a s obzirom na vrstu koronarne restauracije $\left(\chi^{2}=5,000, P=0,082\right.$; tablica 3.).

U tablici 4. prikazana je raspodjela zuba s AP-om u odnosu prema skupini zuba, kvaliteti i vrsti koronarne restauracije. U grupi pretkutnjaka $\left(\chi^{2}=12,872 ; \mathrm{P}=0,002\right)$ i kutnjaka $\left(\chi^{2}=34,468 ; \mathrm{P}<0,001\right)$ utvrđena je značajna razlika u udjelu zuba s dijagnozom AP-a neovisno o kvaliteti koronarne restauracije. U grupi pretkutnjaka AP je češće otkriven u zubima restauriranima krunicama negoli u onima restauriranima amalgamskim $(13,4$ vs. 4,$3 ; \mathrm{P}=0,002)$ ili kompozitnim ispunima $(13,4$ vs. 5,9; $\mathrm{P}=0,003)$. Grupa kutnjaka također je imala češću dijagnozu AP-a u zubima restauriranima krunicama u usporedbi s amalgamskim $(19,0$ vs. 5,$4 ; \mathrm{P}<0,001)$ ili kompozitnim ispunima (19,0 vs. 4,$1 ; \mathrm{P}<0,001)$. No u slučaju koronarne restauracije primjerene kvalitete, samo je u grupi pretkutnjaka uočena značajna razlika s obzirom na vrstu koronarne restauracije $(\chi 2=19,786 ; \mathrm{P}<0,001)$. AP je bio češći u pretkutnjacima opskrbljenima krunicama u usporedbi s amalgamskim ili kompozitnim ispunima ( $11,9 \%$ vs. $1,9 \%$, odnosno $3 \%$; oba P < 0,001; tablica 4).

U tablici 5. su rezultati multivarijantne logističke regresijske analize sa svim opisnim varijablama uključenima u mo-

Table 4 Type and quality of coronal restoration in relation to AP and tooth type

Tablica 4. Vrsta i kvaliteta koronarne restauracije s obzirom na AP i vrstu zuba

\begin{tabular}{|c|c|c|c|c|c|c|c|c|c|}
\hline & \multirow{2}{*}{\multicolumn{3}{|c|}{$\begin{array}{l}\mathrm{AP} \text { in relation to type/material of } \\
\text { restoration } \bullet \mathrm{AP} \mathbf{u} \text { odnosu prema vrsti/ } \\
\text { materijalu restauracije }\end{array}$}} & \multicolumn{6}{|c|}{$\mathrm{AP}$ in relation to restoration quality $\bullet \mathrm{AP} \mathbf{u}$ odnosu prema kvaliteti restauracije } \\
\hline & & & & \multicolumn{3}{|c|}{$\begin{array}{c}\text { Adequate quality • Odgovarajuća } \\
\text { kvaliteta }\end{array}$} & \multicolumn{3}{|c|}{$\begin{array}{c}\text { Inadequate quality • Neodgovarajuća } \\
\text { kvaliteta }\end{array}$} \\
\hline & $\begin{array}{c}\text { Total • } \\
\text { Ukupno }\end{array}$ & AP, n (\%) & $\begin{array}{l}\text { Statistics } \bullet \\
\text { Statistika }\end{array}$ & $\begin{array}{c}\text { Total • } \\
\text { Ukupno }\end{array}$ & AP, $\mathbf{n}(\%)$ & $\begin{array}{l}\text { Statistics } \\
\text { Statistika }\end{array}$ & $\begin{array}{c}\text { Total • } \\
\text { Ukupno }\end{array}$ & $\mathrm{AP}, \mathbf{n}(\%)$ & $\begin{array}{c}\text { Statistics } \\
\text { Statistika }\end{array}$ \\
\hline \multicolumn{10}{|c|}{ Incisors and canines $\bullet$ Sjekutići i očnjaci } \\
\hline Amalgam & 5 & $0(0)$ & \multirow{3}{*}{$\begin{array}{l}\chi^{2}=4.777 \\
P=0.092 \dagger\end{array}$} & 5 & $0(0)$ & \multirow{3}{*}{$\begin{array}{l}\chi^{2}=4.003 \\
P=0.135 \dagger\end{array}$} & 0 & $0(0)$ & \multirow{3}{*}{$\begin{array}{l}\chi^{2}=23.388 \\
P<0.001^{*}\end{array}$} \\
\hline $\begin{array}{l}\text { Composite • } \\
\text { Kompozit }\end{array}$ & 1024 & $45(4.4)$ & & 484 & $15(3.1)$ & & 540 & $30(5.6)$ & \\
\hline Crown $\bullet$ Krunice & 186 & $15(8.1)$ & & 121 & $0(0)$ & & 65 & $15(23.1)$ & \\
\hline Total • Ukupno & 1215 & $60(4.9)$ & & 610 & $15(2.5)$ & & 605 & $45(7.4)$ & \\
\hline \multicolumn{10}{|c|}{ Premolars $\bullet$ Pretkutnjaci } \\
\hline Amalgam & 323 & $14(4.3)$ & \multirow{3}{*}{$\begin{array}{l}\chi^{2}=12.872 \\
\mathrm{P}=0.002^{*}\end{array}$} & 213 & $4(1.9)$ & \multirow{3}{*}{$\begin{array}{l}\chi^{2}=19.786 \\
P<0.001^{*}\end{array}$} & 110 & $10(9.1)$ & \multirow{3}{*}{$\begin{array}{l}\chi^{2}=2.046 \\
\mathrm{P}=0.360 \dagger\end{array}$} \\
\hline $\begin{array}{l}\text { Composite • } \\
\text { Kompozit }\end{array}$ & 1179 & $70(5.9)$ & & 674 & $20(3.0)$ & & 505 & $50(9.9)$ & \\
\hline Crown $\bullet$ Krunice & 119 & $16(13.4) \ddagger$ & & 84 & $10(11.9) \ddagger$ & & 35 & $6(17.1)$ & \\
\hline Total • Ukupno & 1621 & $100(6.2)$ & & 971 & $34(3.5)$ & & 650 & $66(10.2)$ & \\
\hline \multicolumn{10}{|l|}{ Molars $\bullet$ Kutnjaci } \\
\hline Amalgam & 1035 & $56(5.4)$ & \multirow{3}{*}{$\begin{array}{l}\chi^{2}=34.468 \\
P<0.001^{*}\end{array}$} & 550 & $10(1.8)$ & \multirow{3}{*}{$\begin{array}{l}\chi^{2}=4.223 \\
\mathrm{P}=0.121 \dagger\end{array}$} & 485 & $46(9.5)$ & \multirow{3}{*}{$\begin{array}{l}\chi^{2}=29.324 \\
P<0.001^{*}\end{array}$} \\
\hline $\begin{array}{l}\text { Composite } \\
\text { Kompozit }\end{array}$ & 1348 & $55(4.1)$ & & 745 & $5(0.7)$ & & 594 & $50(8.4)$ & \\
\hline Crown $\bullet$ Krunice & 79 & $15(19.0) \ddagger$ & & 34 & $0(0)$ & & 45 & $15(33.3) \ddagger$ & \\
\hline Total・ Ukupno & 2462 & $126(5.1)$ & & 1338 & $15(1.1)$ & & 1124 & $111(9.9)$ & \\
\hline $\begin{array}{l}\text { * Significant differe } \\
\text { vrstu koronarne re } \\
\dagger \text { No significant dif } \\
\text { obzirom na vrstu k } \\
\text { † Sionificant differe }\end{array}$ & ces in freque & cy of teeth wit & AP according & o type of cor & al restoration & Značajne raz & e u učestalo & zuba s AP-on & $\begin{array}{l}\text { s obzirom na } \\
\text { AP-om s }\end{array}$ \\
\hline
\end{tabular}


Table 5 Multivariate logistic regression analysis of tooth-specific variables in relation to AP in restored teeth Tablica 5. Multivarijantna logistička regresijska analiza varijabli specifičnih za zub s obzirom na AP u restauriranim zubima

Variables • Varijable

Type of restoration $\bullet$ Vrsta restauracije

Amalgam

Crown $\bullet$ Krunica
Odds ratio •

Omjer izgleda
$95 \%$ CI Reference $\bullet$ Referentna vrijednost

0.918

3.390

0.672 to 1.255

2.181 to 5.269

0.593

$<0.001$

Marginal integrity of tooth restoration $\bullet$ Rubna cjelovitost zubne restauracije

\begin{tabular}{|c|c|c|c|}
\hline Adequate $\bullet$ Odgovarajuća & 1 & Reference $\bullet$ Referentna vrijednost & \\
\hline Inadequate $\bullet$ Neodgovarajuća & 1.359 & 0.780 to 2.368 & 0.279 \\
\hline \multicolumn{4}{|l|}{ Recurrent caries $\bullet$ Rekurentni karijes } \\
\hline $\mathrm{No} \bullet \mathrm{Ne}$ & 1 & Reference $\bullet$ Referentna vrijednost & \\
\hline Yes $\bullet \mathrm{Da}$ & 4.666 & 2.769 to 7.862 & $<0.001$ \\
\hline \multicolumn{4}{|l|}{ Tooth type $\bullet$ Grupa zuba } \\
\hline Incisors and canines $\bullet$ Sjekutići i očnjaci & 1 & Reference $\bullet$ Referentna vrijednost & \\
\hline Premolars $\bullet$ Pretkutnjaci & 1.725 & 1.217 to 2.446 & 0.002 \\
\hline Molars $\bullet$ Kutnjaci & 1.242 & 0.870 to 1.772 & 0.232 \\
\hline \multicolumn{4}{|c|}{ Marginal bone loss $\bullet$ Gubitak marginalne kosti } \\
\hline$\leq 1 / 3$ root length $\bullet \leq 1 / 3$ dužine korijena & 1 & Reference $\bullet$ Referentna vrijednost & \\
\hline$>1 / 3$ root length $\bullet>1 / 3$ dužine korijena & 1.026 & 0.784 to 1.344 & 0.850 \\
\hline
\end{tabular}

Table 5 demonstrates the results of a multivariate logistic regression analysis with all considered explanatory variables included in the model. A significant positive association was found between the outcome variable, AP and crowns $(\mathrm{OR}=3.39 ; 95 \% \mathrm{CI} 2.2-5.3$; $\mathrm{P}<0.001)$, recurrent caries $(\mathrm{OR}=4.67 ; 95 \%$ CI 2.8 to $7.8 ; \mathrm{P}<0.001)$ and premolars $(\mathrm{OR}=1.73 ; 95 \% \mathrm{CI} 1.2-2.4 ; \mathrm{P}=0.002$; Table 4). The highest association was determined for the presence of recurrent caries. Conversely, it was found that teeth with inadequate marginal integrity of restorations have a slightly increased, but not statistically significant risk for AP presence than teeth with an adequate marginal integrity. Marginal bone loss $>1 / 3$ root length was not statistically associated with an increased risk of AP presence (Table 5).

\section{Discussion}

As in previously conducted surveys $(18,26)$, the present study sample was mainly composed of female subjects (68.2\%). The median number of remaining teeth in the study sample was 26 (interquartile range 24-28), which is also comparable to the previous research (8). Periapical disease was diagnosed in $5.4 \%$ of permanently restored non-endodontically treated teeth. Of the 597 examined participants, 54.3\% had AP in one or more non-endodontically treated teeth. A high prevalence of AP may be attributable to the sampling method. This was a clinically-based study and the sample was drawn from the patients referred to the dental clinic, hence it is likely that the prevalence of periapical disease is higher than the prevalence expected in general population (19). Yet, this study aimed to disclose the relation between the type of coronal restoration and periapical disease in non-endodontically treated teeth, and the method of sampling was not considered to have a crucial effect on the results.

The present survey focused on the quality of coronal restoration and periapical status at the time of the examination. del. Značajna pozitivna povezanost uočena je između ishodišne varijable $\mathrm{AP}$-a i krunica $(\mathrm{OR}=3,39 ; 95 \% \mathrm{CI} 2,2-5,3$; $\mathrm{P}<0,001)$, rekurentnog karijesa $(\mathrm{OR}=4,67 ; 95 \% \mathrm{CI} 2,8$ $-7,8 ; \mathrm{P}<0,001)$ te pretkutnjaka $(\mathrm{OR}=1,73 ; 95 \% \mathrm{CI} 1,2$ $-2,4 ; \mathrm{P}=0,002$; tablica 4.). Najveća povezanost utvrđena je za varijablu rekurentnog karijesa. Suprotno tomu, na zubima kojima rubna cjelovitost restauracije nije bila primjerena utvrđen je blago povećan, ali statistički neznačajan rizik od $A P-a$ u usporedbi sa zubima s primjerenom kvalitetom ruba restauracije. Gubitak marginalne kosti >1/3 dužine korijena nije bio statistički značajan za prisutnost AP-a (tablica 5.).

\section{Rasprava}

Kao i u dosadašnjim studijama $(18,26)$ većinu ispitanika činile su žene (68,2\%). Medijan broja preostalih zuba u uzorku bio je 26 (interkvartilni raspon 24 -28), što je također usporedivo $s$ dosadašnjim istraživanjem (8). Periapikalna bolest dijagnosticirana je u 5,4 \% trajno restauriranih endodontski neliječenih zuba. U uzorku od 597 pregledanih ispitanika, 54,3\% imalo je AP jednoga ili više endodontski neliječenih zuba. Visoka učestalost AP-a može se pripisati metodi uzorkovanja. U ovom slučaju bila je riječ o kliničkom istraživanju u kojemu se uzorak dobio iz populacije pacijenata upućenih na dentalnu kliniku te je učestalost periapikalne bolesti u odnosu prema općoj populaciji očekivano veća (19). Ipak, u ovom istraživanju težilo se otkriti povezanost između vrste koronarne restauracije i periapikalne bolesti u endodontski neliječenim zubima. Zato se smatralo da metoda uzorkovanja nije bila presudna za ishod rezultata.

Ovo istraživanje bilo je usredotočeno na analizu kvalitete koronarne restauracije i periapikalne bolesti u vrijeme pregleda. Hipoteza je bila da nema značajne razlike u periapikal- 
The hypothesis was that there is no significant difference in the periapical status of non-endodontically treated teeth regarding the type or material of permanent coronal restoration. Indeed, the analysis of teeth with adequate quality of coronal restoration did not found any significant difference in the frequency of AP regarding the type of coronal restoration. Although some experimental studies have revealed some harmful effects of resin composite on pulpal cells, this does not seem to be the case when it is used for restorations in clinical conditions $(8,22,23)$. Our study demonstrated that there are no differences in the prevalence of AP between teeth restored with amalgam and resin composite, irrelevant of their quality, which is consistent with the results of the previously cited study (8).

When periapical status was analyzed according to the tooth type, only the group of premolars demonstrated a significant difference regarding the type of coronal restoration. AP was more frequent in premolars restored with crowns, than in those restored with amalgam or composite fillings. An interesting observation was that frontal and molar teeth restored with crowns of adequate quality had no periapical diseases. In contrast, almost $12 \%$ of premolars with adequate crowns had AP. Arguably, cumulative insults on dental pulp, such as caries, restorative treatments, periodontal disease and trauma may have diminished a long-term prognosis for pulpal vitality in these teeth (12). They had possibly impaired the pulp ability to recover from further trauma that resulted from preparation to receive crowns. Furthermore, tooth preparation for full coverage crowns necessitates more extensive tooth structure removal than for other restoration types. The integrity and vitality of the pulp may also be impaired due to desiccation of dentin and development of frictional heat or exothermic reactions during setting of impression materials, acrylic resins and luting cements (24). While certain studies found no variation in incidence of the pulp necrosis regarding the tooth type, Cheung at al. reported that majority of pulpal necroses developed in the maxillary anterior teeth that served as bridge abutments $(12,25)$.

The results regarding the differences in periapical status according to the type and quality of coronal restoration, as well as tooth type, were obtained using a bivariate analysis (chisquare test). Since more than one variable affects the course of disease, multivariate models are better approximation to reality, allowing for judgement of the relative importance of each predictor variable. There are variables that could have influenced the results but could not have been controlled due to the cross-sectional nature of the study, such as time of restoration placement, and pulpal and periapical status that preceded the restoration placement. Therefore, this study could only identify risk indicators for AP presence in restored teeth. $A$ variable is designated as a risk indicator when its presence increases the individual's risk of exhibiting periapical disease. However, risk indicators may, but need not, be directly associated with the disease $(3,21)$. Bearing in mind the previously mentioned limitations, logistic regression was used to analyze the simultaneous influence of predictor variables on $\mathrm{AP}$ presence. This analysis disclosed several possible risk indicators for $\mathrm{AP}$ presence. An increased risk for AP presence was nom statusu endodontski neliječenih zuba s obzirom na vrstu i materijal trajne restauracije. $U$ analizi zuba s koronarnim restauracijama odgovarajuće kvalitete nije uočena značajna razlika u učestalosti AP-a s obzirom na vrstu koronarne restauracije. Iako su neka eksperimentalna istraživanja upućivala na štetan učinak smolastih kompozitnih materijala na stanice zubne pulpe, čini se da to nije slučaj ako se ti materijali upotrebljavaju u kliničkim uvjetima $(8,22,23)$. U skladu s nalazima prije navedenog istraživanja, i naše je pokazalo da nema razlike u učestalosti AP-a između zuba restauriranih amalgamom i kompozitom, neovisno o kvaliteti ispuna (8).

$\mathrm{U}$ analizi periapikalnog statusa $s$ obzirom na skupinu zuba, samo je na pretkutnjacima uočena značajna razlika u odnosu prema vrsti koronarne restauracije. AP je bio češći na pretkutnjacima koji su restaurirani krunicama negoli na onima $s$ amalgamskim ili kompozitnim ispunima. Zanimljivo, na prednjim zubima i kutnjacima restauriranima krunicama odgovarajuće kvalitete nije zabilježena periapikalna bolest. $S$ druge strane, gotovo $12 \%$ pretkutnjaka restauriranih krunicama odgovarajuće kvalitete imalo je AP. Moguće je da su skupni štetni učinci na dentalnu pulpu, poput karijesa, restaurativnog liječenja, parodontne bolesti i traume, mogli umanjiti dugoročnu prognozu vitalnosti pulpe u tim zubima (12). Vjerojatno je da su ti zubi imali smanjenu regenerativnu sposobnost zubne pulpe potrebnu za oporavak nakon daljnje traume učinjene preparacijom za krunice. Nadalje, preparacija zuba za potpune krunice zahtijeva opsežnije uklanjanje zubne strukture u usporedbi s ostalim vrstama restauracija. Integritet i vitalitet pulpe također mogu biti ugroženi zbog isušivanja dentina, nastanka frikcijske topline ili egzotermne reakcije tijekom stvrdnjavanja materijala za otiske, akrilatne smole ili cemenata (24). U određenom studijama autori nisu našli razlike $\mathrm{u}$ incidenciji nekroze pulpe s obzirom na skupinu zuba, ali je u istraživanju Cheunga i suradnika uočeno da se nekroza pulpe najčěśce pojavljivala na prednjim zubima gornje čeljusti koji su bili nosači fiksnih protetičkih nadomjestaka $(12,25)$.

Rezultati koji se odnose na analizu razlike u periapikalnom statusu s obzirom na vrstu i kvalitetu koronarne restauracije te skupine zuba, dobiveni su bivarijantnom analizom (Hi-kvadrat test). S obzirom na to da više varijabli utječe na tijek bolesti, multivarijantni modeli bolji su prikaz stvarne situacije jer omogućuju procjenu relativne važnosti svake prediktivne varijable. Varijable poput vremena u kojem je izradena restauracija te pulpnoga i periapikalnoga statusa prije postavljanja restauracije mogle su utjecati na rezultate studije, ali one se nisu mogle kontrolirati zbog presječnog dizajna studije. Zato se u ovom istraživanju moglo samo identificirati pokazatelje rizika od pojave AP-a na restauriranim zubima. Varijabla je prepoznata kao pokazatelj rizika ako je njezina pojava kod ispitanika povećala rizik od pojave periapikalne bolesti. Ipak, pokazatelji rizika mogu, ali ne moraju, biti izravno povezani s bolešćc $(3,21)$. Imajući na umu prije navedena ograničenja, korištena je logistička regresija u analizi istodobnog utjecaja prediktorskih varijabli na pojavu AP-a. Otkriveno je nekoliko mogućih pokazatelja rizika za pojavu AP-a. Povećani rizik od AP-a uočen je u skupini pretkutnjaka, zuba restauriranih krunicama te na zubima s kliničkom ili 
found for premolars, crowned teeth and teeth with clinical or radiological diagnosis of recurrent caries. Compared to group of incisors and canines, premolars were 1.7 times more likely to have AP. Teeth restored with crowns were 3.4 times more likely to have AP than teeth restored with amalgam fillings. Interestingly, teeth with inadequate marginal integrity of restorations had a slightly increased, but not statistically significant risk for $\mathrm{AP}$ presence. In turn, the presence of recurrent caries demonstrated the highest association and increased the risk for radiologic diagnosis of AP 4.7 times. Contrary to the previously conducted studies, marginal bone loss was not associated with the presence of periapical disease $(3,8)$. While full coverage crowns seemed to have a positive effect on periapical health in endodontically treated teeth (26), the present results indicated crowns as a risk indicator for poor periapical status in non-endodontically treated teeth. A possible explanation for this finding may be that the teeth that were restored with crowns were originally more compromised due to caries or fractures, than the teeth that were restored with direct restorations and therefore more prone to develop AP. In such a case, the AP would not be related to crowns but to the pre-existing compromised tooth structure.

A study by Hommez et al. demonstrated that the evaluation of coronal restoration quality based merely on radiographic images analysis did not provide adequate data; hence their study emphasized the importance of supplementation of radiographic information with clinical data (27). In the present research, the assessment of the quality of the coronal restorations was based on both clinical and radiographic recordings.

This survey has several issues that might have led to underestimation of periapical pathosis. First, the cross-sectional design of the study precludes the follow-up of the periapical disease dynamics, while the frequency of AP depends on a period for the disease progress or regress. In the present study, PAI was used for AP diagnosis. A strict calibration procedure of observers and the use of visual references with verified histologic diagnoses enable higher reproducibility of the radiographic scores $(17,28)$. However, as in other studies of similar design, the present survey did not involve clinical criteria for AP diagnosis, and this might inevitably lead to underestimation of periapical pathosis $(2-4,19-21)$. Since histological studies demonstrated that periapical inflammation may be associated with absence of radiographic signs (29), it is important to use the most sensitive diagnostic tool to identify AP. Cone beam computed tomography (CBCT) has excellent accuracy in AP diagnostics when compared to conventional radiographs (30). However, as it results in a higher radiation dose, CBCT use in endodontics should be limited to cases when conventional radiographic techniques do not provide sufficient information for confident diagnosis and treatment planning $(31,32)$. Due to lower radiation dose compared with a full-mouth survey, panoramic radiographs were chosen for the evaluation of periapical status in the present study. It has been shown that the prevalence of AP may be underestimated when compared to periapical radiography. However, when compared to cone beam computed tomography, both panoramic and periapical radiographs correctly identify AP in advanced stages (33). radiološkom dijagnozom rekurentnog karijesa. U usporedbi sa skupinom sjekutića i očnjaka, pretkutnjaci su imali $1,7 \mathrm{pu}-$ ta veću vjerojatnost za nalaz AP-a. Zubi restaurirani krunicama imali su 3,4 puta veću vjerojatnost za pojavu AP-a negoli oni s amalgamskim ispunima. Zanimljivo, zubi s neadekvatnom rubnom cjelovitošću restauracije imali su malo povećan, ali statistički neznačajan rizik od pojave AP-a. No pokazalo se da nalaz rekurentnog karijesa ima najveću povezanost te 4,7 puta povećava rizik za radiološku dijagnozu AP-a. Suprotno prije provedenim istraživanjima, gubitak marginalne kosti nije bio povezan s nalazom periapikalne bolesti $(3,8)$. Iako je u prethodnoj studiji istaknuto da potpune krunice pozitivno utječu na zdravlje periapikalnih tkiva endodontski liječenih zuba (26), u ovom su istraživanju krunice prepoznate kao indikator rizika za loš periapikalni status endodontski neliječenih zuba. Moguće objašnjenje za taj nalaz mogla bi biti veća preoperativna oštećenja karijesom ili frakturama zuba koji su zatim restaurirani krunicama i slijedom toga skloniji pojavi $A P$-a. U tom slučaju AP ne bi bio povezan s krunicama, nego $s$ postojećim oštećenjima zubne strukture.

U istraživanju Hommeza i suradnika procjena kvalitete koronarne restauracije temelji se isključivo na radiološkoj analizi snimaka. Takvo istraživanje ne daje dovoljno podataka te je istaknuta važnost prikupljanja kliničkih informacija uz radiološke snimke (27).

Ovo istraživanje ima nekoliko ograničenja koja su mogla prouzročiti podcjenjivanje periapikalne patologije. Istaknimo da presječni dizajn studije onemogućuje praćenje dinamike periapikalne bolesti, a frekvencija AP-a ovisi o razdoblju napredovanja ili regresije bolesti. PAI je korišten u dijagnozi AP-a. Dosljedan postupak kalibracije i korištenje vizualnih referencija s potvrđenim histološkim dijagnozama omogućuju veću reproducibilnost radioloških nalaza $(17,28)$. Ipak, u sadašnju studiju, kao i u druge slične, nisu uključeni klinički kriteriji za dijagnozu AP-a, što bi moglo voditi u podcjenjivanje učestalosti periapikalne patologije $(2-4,19-21)$. $S$ obzirom na to da je u histološkim istraživanjima utvrđena mogućnost nalaza periapikalne upale bez radioloških znakova (29), važno je koristiti se osjetljivim dijagnostičkim sredstvima u otkrivanju AP-a. Kompjutorska 3D tomografija (CBCT) zbog preciznosti je izvrsna u dijagnostici AP-a u usporedbi s konvencionalnim radiogramima (30). Ipak, CBCT dijagnostika uključuje i veću količinu zračenja te bi njezina upotreba trebala biti ograničena na slučajeve kada konvencionalne radiološke tehnike ne pružaju pouzdane informacije za postavljanje dijagnoze i planiranje liječenja $(31,32)$. U ovom istraživanju su panoramske snimke korištene $u$ analizi periapikalnog statusa zbog manjeg zračenja u usporedbi $s$ izradom periapikalnih snimki svih zuba. Analizom panoramskih snimki učestalost AP-a može biti podcijenjena u usporedbi s periapikalnim snimkama. Ipak, u usporedbi s CBCTom, panoramske i periapikalne snimke točno su utvrdile AP u napredovalim stadijima bolesti (33).

U nekoliko opsežnih istraživanja o oralnome zdravlju autori su se koristili panoramskim snimkama kao metodom izbora za procjenu periapikalnog statusa $(8,34,35)$. Panoramski radiogrami omogućuju pregled svih zuba na jedinstvenoj radiološkoj snimci uz nižu dozu zračenja u usporedbi $s$ izra- 
Several comprehensive studies regarding oral health that preceded our research utilized the panoramic radiographs as a radiographic technique of choice for periapical status evaluation $(8,34,35)$. Panoramic radiographs allow the examination of all teeth in a single radiographic image under low radiation doses when compared to full mouth periapical radiography, and therefore are acceptable and frequently used for the evaluation of AP in epidemiological studies $(2,26$, 34-36).

Although the data reported in the present study suggested that crowns may be a risk indicator for the presence of $A P$ in non-endodontically treated teeth, the fact that the pulpal and periapical status at the time of restoration placement were unknown makes impossible to know if the AP was pre-existing or developed after the restoration was inserted. Therefore, to determine a causal-effective relationship between the type of coronal restoration and periapical disease, a prospective design of study should be applied, preferably by using a limited cone beam computed tomography for AP diagnosis.

\section{Conclusion}

The results of this research supported our hypothesis. If the quality of restorations is adequate, there is no difference in the periapical status of non-endodontically treated teeth regarding the type and material of coronal restoration.

\section{Acknowledgments}

This work was supported by a funding grant from the University of Rijeka, Croatia (grant no. 818101218). Professor Dag Ørstavik is acknowledged for providing PAI calibration kit.

\section{Disclosure}

Authors deny any conflict of interest.

Author's contribution: R. P. B. - performed a radiological analysis of periapical status and marginal bone loss, statistical analysis, interpretation of data, and she drafted the manuscript; E. P. - performed clinical data acquisition and drafted the manuscript; S. P. R. - co-designed the concept and methodology of the study and edited the manuscript; I. B. P. - co-designed the concept and methodology of the study and reviewed the manuscript. dom periapikalnih snimki svih zuba, stoga su prikladni i često se primjenjuju u analizi AP-a u epidemiološkim studijama $(2,26,34-36)$.

Iako podatci u ovom istraživanju upućuju na krunice kao pokazatelje rizika za AP u slučaju endodontski neliječenih zuba, nemoguće je znati je li AP bio postojeće stanje ili se pojavio nakon postavljanja restauracije zbog nepotpunih podataka o pulpnom i periapikalnom statusu u trenutku postavljanja restauracije. Zbog otkrivanja uzročno-posljedičnog odnosa između vrste restauracije i periapikalne bolesti potrebno je provesti prospektivnu studiju koristeći se, ako je moguće, CBCT-om u dijagnozi AP-a.

\section{Zaključak}

Rezultati ovog istraživanja potvrdili su našu hipotezu. Ako je kvaliteta restauracije odgovarajuća, nema razlike u periapikalnom statusu endodontski neliječenih zuba s obzirom na vrstu i materijal koronarne restauracije.

\section{Zahvale}

Ovaj rad financijski je poduprlo Sveučilišste u Rijeci (potpora br. 818101218). Autori zahvaljuju profesoru Dagu Ørstaviku na osiguranom alatu za PAI kalibraciju.

\section{Sukob interesa}

Autori izjavljuju da nisu u bili sukobu interesa.

Doprinos autora: R. P. B. - provela je radiološku analizu periapikalnog statusa i gubitka marginalne kosti, statističku analizu i tumačenje podataka, te priredila rukopis; E. P. prikupila je kliničke podatke i priredila rukopis; S. P. R. sudjelovala je u planiranju koncepta i metodologije istraživanja, te je uredila rukopis: I. B. P. - sudjelovala je u planiranju koncepta i metodologije istraživanja, te je pregledala i kritički ocijenila rukopis. 


\section{Sažetak}

Cilj: Svrha studije bila je usporediti učestalost apikalnog parodontitisa (AP) u endodontski neliječenim zubima koji su restaurirani potpunim krunicama te amalgamskim i smolastim kompozitnim ispunima. Također je istraživana povezanost vrste i kvalitete koronarne restauracije s prisutnošću periapikalne bolesti. Materijali i postupci: Presječno istraživanje obuhvatilo je 597 ispitanika koji su prvi put posjetili Kliniku za dentalnu medicinu Kliničkoga bolničkog centra Rijeka. Podatci su prikupljen kliničkim i radiološkim pregledom. Za sve trajno restaurirane endodontski neliječene zube analizirani su vrsta, kvaliteta koronarne restauracije prema kliničkim i radiološkim kriterijima za rubnu cjelovitost restauracije i prisutnost rekurentnog karijesa, periapikalni status te gubitak marginalne kosti. Hi-kvadrat testovi primijenjeni su u analizi razlike periapikalnog statusa s obzirom na vrstu i kvalitetu restauracije. Multivarijantna logistička regresijska analiza obavljena je u procjeni utjecaja prediktorskih dentalnih varijabli na periapikalni status. Rezultati: Nije dokazana značajna razlika u proporciji AP-a s obzirom na vrstu i materijal koronarne restauracije odgovarajuće kvalitete $\left(\chi^{2}=5,000\right.$, $P=0,082)$. Regresijskom analizom otkrivena je značajna pozitivna povezanost s ishodišnom varijablom $(A P)$ za krunice $(O R=3,39 ; P<0,001)$, rekurentni karijes $(O R=4,67 ; P<0,001)$ i pretkutnjake $(O R=1,73 ; P=0,002)$. Zaključak: Ako su restauracije primjerene kvalitete, nema razlike u periapikalnom statusu endodontski neliječenih zuba s obzirom na vrstu i materijal korišten za koronarne restauracije.
Zaprimljen: 20. lipnja 2020.

Prihvaćen: 4. siječnja 2021.

Adresa za dopisivanje

Romana Peršić Bukmir, DMD, Ph. D.*

Klinički bolnički centar Rijeka,

Sveučilište u Rijeci, Rijeka, Hrvatska

Fakultet dentalne medicine,

Zavod za endodonciju i restaurativnu stomatologiju,

ORCID: 0000-0002-5325-6726

Krešimirova 40, 51000 Rijeka,

Hrvatska

tel: +38551345635

faks: +385 51345630

rpersic@gmail.com

MeSH pojmovi: kruna zuba; trajni zubni ispun; zubni amalgam; kompozitne smole; periapikalni parodontitis Autorske ključne riječi: kompozitni materijali, krunice, dentalni amalgam, dentalni karijes, apikalni parodontitis

\section{References}

1. Chala S, Abouqal R, Abdallaoui F. Prevalence of apical periodon titis and factors associated with the periradicular status. Acta Odontol Scand. 2011 Nov;69(6):355-9.

2. Matijevic J, Cizmekovic Dadic T, Prpic Mehicic G, Anic I, Slaj M, Ju kic Krmek S. Prevalence of apical periodontitis and quality of root canal fillings in population of Zagreb, Croatia: a cross-sectional study. Croat Med J. 2011 Dec 15;52(6):679-87.

3. Kirkevang LL, Vaeth M, Wenzel A. Tooth-specific risk indicators for apical periodontitis. Oral Surg Oral Med Oral Pathol Oral Radiol Endod. 2004;97(6):739-44.

4. Kirkevang LL, Vaeth M, Hörsted-Bindslev P, Bahrami G, Wenzel A. Risk factors for developing apical periodontitis in a general population. Int Endod J. 2007 Apr;40(4):290-9.

5. Pinna R, Usai P, Filigheddu E, Garcia-Godoy F, Milia E. The role of adhesive materials and oral biofilm in the failure of adhesive res in restorations. Am J Dent. 2017 Oct;30(5):285-292.

6. MeSH Browser [database on the Internet]. Rasines Alcaraz MG Veitz-Keenan A, Sahrmann P, Schmidlin PR, Davis D, Iheozor-Ejiofor Z. Direct composite resin fillings versus amalgam fillings for permanent or adult posterior teeth. Cochrane Database Syst Rev. [serial on the Internet]. 2014 Mar. [cited 2020 Jun 20]; (3): [about 48 p.]. Available from: https://doi.org/10.1002/14651858. CD005620.

7. Albeshti R, Shahid S. Evaluation of Microleakage in Zirconomer®: A Zirconia Reinforced Glass Ionomer Cement. Acta Stomatol Croat. 2018;52(2):97-104.

8. Dawson V, Petersson K, Wolf E, Akerman S. Periapical status of non-root-filled teeth with resin composite, amalgam, or full crown restorations: a cross-sectional study of a Swedish adult population. J Endod. 2014 Sep;40(9):1303-8.

9. Lockard MW. A retrospective study of pulpal response in vital adult teeth prepared for complete coverage restorations at ultrahigh speed using only air coolant. J Prosthet Dent. 2002 Nov;88(5):473-8.

10. Valderhaug J, Jokstad A, Ambjørnsen E, Norheim PW. Assessment of the periapical and clinical status of crowned teeth over 25 years. J Dent. 1997; 25(2):97-105.

11. Sigal AV, Sigal MJ, Titley KC, Andrews PB. Stainless steel crowns as a restoration for permanent posterior teeth in people with special needs: A retrospective study. J Am Dent Assoc. 2020 Feb;151(2):136-144

12. Cheung GS, Lai SC, Ng RP. Fate of vital pulps beneath a metal-ceramic crown or a bridge retainer. Int Endod J. 2005 Aug;38(8):521 30.

13. World Health Organization. Oral health survey-basic methods, 4th ed. Geneva, Switzerland: World Health Organization; 1997.

14. Merdad K, Sonbul H, Bukhary S, Reit C, Birkhed D. Caries susceptibility of endodontically versus nonendodontically treated teeth. J Endod. 2011;37(2):139-42.
15. Segura-Egea IJ, Jiménez-Pinzón A, Poyato-Ferrera M, VelascoOrtega E, Ríos-Santos JV. Periapical Status and Quality of Root Fillings and Coronal Restorations in an Adult Spanish Population. Int Endod J. 2004 Aug;37(8):525-30.

16. Frisk F, Hugosson A, Kvist T. Is Apical Periodontitis in Root Filled Teeth Associated With the Type of Restoration? Acta Odontol Scand. 2015 Apr;73(3):169-75.

17. Ørstavik D, Kerekes K, Eriksen HM. The periapical index: A scoring system for radiographic assessment of apical periodontitis. Endod Dent Traumatol. 1986 Feb;2(1):20-34.

18. Paloma de Oliveira B, Câmara AC, Aguiar CM. Prevalence of Asymptomatic Apical Periodontitis and its Association with Coronary Artery Disease in a Brazilian Subpopulation. Acta Stomato Croat. 2017;51(2):106-112.

19. Aleksejuniene J, Eriksen HM, Sidaravicius B, Haapasalo M. Apical periodontitis and related factors in an adult Lithuanian pop ulation. Oral Surg Oral Med Oral Pathol Oral Radiol Endod. 2000 Jul;90(1):95-101.

20. Romana Persic Bukmir, Jelena Vidas, Diana Mance, Sonja PezeljRibaric, Stjepan Spalj, Ivana Brekalo Prso. Socio-economic and health status as a predictor of apical periodontitis in adult patients in Croatia. Oral Dis. 2019;25(1):300-8.

21. Kirkevang LL, Wenzel A. Risk indicators for apical periodontitis. Community Dent Oral Epidemiol. 2003 Feb;31(1):59-67.

22. Galler KM, Schweikl H, Hiller KA, Cavender AC, Bolay C, D'Souza $\mathrm{RN}$, et al. TEGDMA reduces mineralization in dental pulp cells. J Dent Res. 2011 Feb;90(2):257-62.

23. Krifka S, Seidenader C, Hiller KA, Schmalz G, Schweikl H. Oxida tive stress and cytotoxicity generated by dental composites in human pulp cells. Clin Oral Investig. 2012 Feb;16(1):215-24.

24. Sukapattee M, Wanachantararak S, Sirimaharaj V, Vongsavan N, Matthews B. Effect of full crown preparation on pulpal blood flow in man. Arch Oral Biol. 2016;70:111-6.

25. Kontakiotis EG, Filippatos CG, Stefopoulos S, Tzanetakis GN. A prospective study of the incidence of asymptomatic pulp necrosis following crown preparation. Int Endod J. 2015 Jun;48(6):512-7.

26. MeSH Browser [database on the Internet]. Kielbassa AM, Frank W, Madaus T. Radiologic assessment of quality of root canal fillings and periapical status in an Austrian subpopulation - An observational study. PLoS One. [serial on the Internet]. 2017 May [cited 2020 Jun 20]; 12(5): [about 19 p.] Available from: https:// doi.org/10.1371/journal.pone.0176724

27. Hommez GM, Coppens CR, De Moor RJ. Periapical health related to the quality of coronal restorations and root fillings. Int Endod I. 2002 Aug;35(8):680-9.

28. Ørstavik D. Reliability of the periapical index scoring system. Scand J Dent Res. 1988;96(2):108-11.

29. Brynolf I. A histological and roentgenologieal study of the periapical region of human upper incisors. Odontol Revy 1967;18:(Suppl 11). 
30. Leonardi Dutra K, Haas L, Porporatti AL, Flores-Mir C, Nascimento Santos J, Mezzomo LA, et al. Diagnostic Accuracy of Cone-beam Computed Tomography and Conventional Radiography on Apical Periodontitis: A Systematic Review and Meta-analysis. J Endod. 2016 Mar;42(3):356-64.

31. European Society of Endodontology position statement: Use of cone beam computed tomography in Endodontics. Int Endod J. 2019 Dec;52(12):1675-1678

32. American Association of Endodontists, American Academy of Oral and Maxillofacial Radiology. Use of cone-beam computed tomography in endodontics. Joint Position Statement of the American Association of Endodontists and the American Academy of Oral and Maxillofacial Radiology. Oral Surg Oral Med Oral Pathol Oral Radiol Endod. 2011;111:234-7.
33. Estrela C, Bueno MR, Leles CR, Azevedo B, Azevedo JR. Accuracy of cone beam computed tomography and panoramic and periapical radiography for detection of apical periodontitis. J Endod. 2008 Mar;34(3):273-9.

34. Lundegren N, Axtelius B, Akerman S. Oral health in the adult population of Skåne, Sweden: a clinical study. Acta Odontol Scand. 2012;70(6):511-9.

35. Dawson VS, Petersson K, Wolf E, Åkerman S. Periapical Status of Root-filled Teeth Restored with Composite, Amalgam, or Full Crown Restorations: A Cross-sectional Study of a Swedish Adult Population. J Endod. 2016 Sep;42(9):1326-33.

36. Ahlqwist M, Halling A, Hollender L. Rotational panoramic radiography in epidemiological studies of dental health. Comparison between panoramic radiographs and intraoral full mouth surveys. Swed Dent J. 1986;10:73-84. 